\title{
Ethnicity and Mixed Ethnicity: Educational Gaps among Israeli-born Jews ${ }^{1}$ Yinon Cohen, Yitchak Haberfeld, and Tali Kristal \\ Tel Aviv University
}

\begin{abstract}
This paper analyzes gaps in the university graduation rates of third-generation Ashkenazim and Mizrahim (the two major ethnic groups among Israeli Jews), in comparison to the same gaps among members of the second generation. The empirical analyses have been performed using a special file of the 1995 Israeli census which matched records of respondents to their parents in the 1983 Census, thereby allowing identification of the ethnicity of the third generation for a representative sample of men and women, 25-34 years of age in 1995, as well as the identification of persons of mixed ethnicity. The results suggest that the gaps between the two major ethnic groups are not smaller in the third generation than in the second generation. Persons of mixed ethnicity - of both the second and third generations - are located about midway between the two ethnic groups with respect to their university graduation rates. Much of the ethnic-based gap in university graduation is due to differences in family background, especially among women. We discuss the implications of these results for the future of ethnicbased stratification in Israel.
\end{abstract}

\section{Introduction}

Israeli Jewish society is characterized by an ethnic cleavage between Jews who immigrated to Israel from Europe and America (henceforth, Ashkenazim), and those from Asia and Africa (henceforth, Mizrahim). There are persisting socioeconomic gaps between Ashkenazim, who have achieved high levels of education and earnings, and their Mizrahi counterparts, who have never caught up with them or with native-born Israelis. Moreover, the gaps between the two immigrant groups with respect to the main socioeconomic measures, university graduation and earnings, seem to be as persistent among the immigrants' offspring (henceforth, secondgeneration immigrants) as among the immigrants themselves.

${ }^{1}$ This research was partly supported by the Israel Science Foundation (grant number 919/04). We thank Hanna Ayalon, Hadas Mandel, Barbara Okun, Joel Perlmann, and Yossi Shavit for their comments on earlier versions of this paper. 
Ethnic origin is defined by the Israeli Central Bureau of Statistics (CBS) strictly by one's country of birth, and for the Israeli-born, by father's country of birth. Consequently, members of the third generation (Israeli-born with Israeli-born fathers) - close to one third of the Jewish population in 2002 - are defined in official statistics as being of 'Israeli origin' (Cohen 2002). The reliance on parents' country of birth as the sole indicator of ethnicity, together with the decision to trace it back only one generation, results in the elimination of ancestry and ethnicity from official statistics within two generations, or about fifty years. Moreover, relying on the country of birth of one parent only (usually the father) dictates a binary ethnic classification, whereas increasing numbers of Israeli-born Jews are of mixed ethnicity (i.e., one of their parents is Ashkenazi and the other Mizrahi). Eliminating ethnic groupings (and with them ethnic gaps) and adopting an unequivocal 'Israeli' identity have been central goals of the Israeli melting pot. However, this kind of administrative 'Israelization' limits the ability of researchers to test whether or not the socioeconomic gaps in the third generation have indeed disappeared, or at least narrowed.

Fortunately, the CBS created a file that enables the identification of the ethnic origin of third-generation Israelis. This paper utilizes this data set to describe and analyze the relative size of ethnic groups and the schooling levels among the cohort of Israeli Jews who were born in Israel between 1961 and 1970, according to their ethnic origin. Specifically, the paper presents analyses of the gaps in schooling levels between third-generation Ashkenazim and Mizrahim in Israel, in comparison to the gaps among members of the second generation. In addition, unlike previous research, which was forced to classify all Israeli-born Jews as of either one or the other ethnic origin, our data enable us to study a third group of Israeli-Jews, those of mixed 
(Ashkenazi-Mizrahi) ethnic origin. ${ }^{2}$ Although interethnic marriages are considered as the ultimate indicator for immigrants' assimilation (Gordon 1964, Waters and Jimenez 2005), the implications of such marriages for the socioeconomic mobility of their children has been somewhat neglected, in large part because of lack of suitable data. The data available in Israel enable us not only to answer the outstanding question about the ethnic gaps among third generation Israelis, but also to contribute to the more general question of the educational fortunes of offspring of interethnic families.

The paper is organized as follows: the first section briefly reviews the literature regarding the development of ethnic gaps in Israel. The second section presents the data and measures used in the analyses. The third section presents descriptive statistics regarding the gaps in university graduation between the three ethnic groups, by generation, gender and age groups, as well as the relative size of the three ethnic groups. The fourth section presents multivariate analyses aimed at understanding the factors contributing to gaps in educational attainment between the ethnic groups. The final section discusses the results and their implications for ethnic stratification in Israel as well as in other immigrant societies.

\section{The Ethnic Cleavage in Israeli-Jewish Society}

The ethnic cleavage in Israeli-Jewish society dates back to the pre-State years in the first half of the $20^{\text {th }}$ century (Khazzoom 2003). In 1948, the newly established state of Israel had a population of about 650,000 Jews, mostly Ashkenazim with a sizable minority of about 20 per cent Mizrahim. During the next three-and-a-half years after statehood, this relatively small

${ }^{2}$ Israeli Arabs are not considered in this paper because they are neither immigrants nor the children of immigrants. Moreover, since the number of Arab-Jewish marriages is very small, there are virtually no persons of mixed Arab/Jewish ethnicity in Israel. 
Jewish population base actively attracted nearly 700,000 Jewish immigrants. About half the immigrants were survivors of the Jewish Holocaust in Europe. The other half of this immigration wave, known as the 'mass migration,' consisted of Jewish residents of Arab countries in Asia (the majority) and North Africa. Following a short-lived decline in 1952-1953, immigration continued, albeit at a slower pace. During the next 25 years an additional 800,000 Jews immigrated to Israel. About 45 per cent of them came from Europe, America and Australia, and 55 per cent from Arab countries in Asia and especially North Africa.

The social, economic, and cultural assimilation of most Ashkenazi immigrants in Israeli society was rapid and complete. By 1975, their schooling, occupations and earnings were no different than those of native-born Israelis or of veteran immigrants who arrived in Israel during the pre-state period (Boyd, Featherman and Matras 1980). By contrast, Mizrahi immigrants had failed to achieve parity with the native population. Thus, while in other migration societies (U.S.A., Canada, and Australia) the earnings differences between most immigrant groups and natives of similar characteristics disappeared after 11-14 years (Chiswick 1978), Mizrahi immigrants, both those who arrived during the pre-state years and those who arrived in later waves, have failed to close the socioeconomic gaps between them and the other groups Ashkenazi immigrants and native Israelis.

Bad as the experience of first-generation Mizrahi immigrants was, it could be explained by the relatively low level of economic development of the countries of origin from which they came (Semyonov and Lerenthal 1991). But the persistence of socioeconomic gaps among the Israeli-born children of these immigrants (i.e. the second generation) is more difficult to explain. It is beyond the scope of this paper to review all the studies providing macro-sociological explanations for the persistence of the ethnic cleavage in the second generation (e.g., Spilerman 
and Habib 1976; Smooha 1978; Ben Rafael 1982; Swirski 1999; Khazzoom 2003). More important for our purpose are the empirical findings of studies tracing and documenting developments in socioeconomic gaps across time and generations (e.g., Peres 1971; Smooha and Kraus 1985; Nahon 1987; Semyonov and Lerenthal 1991; Mark 1996; Cohen and Haberfeld 1998; Yaish 2001; Friedlander et al. 2002; Yaar 2005).

Despite the many differences between these empirical studies regarding methodology, measures of socioeconomic success, data sets, and the researchers' discipline, there is a consensus that in many spheres of life (labor force participation, marriage patterns, fertility rates, political representation, and rates of high school graduation) the ethnic gap narrowed significantly or disappeared in the second generation. However, the few studies that focused on university graduation rates and labor market earnings - arguably the two most important indicators for social standing in contemporary Israel - found that the gaps between the Israeliborn of Mizrahi and Ashkenazi origin had not been attenuated, as compared to the differences found among their Mizrahi and Ashkenazi parents. Put differently, despite expectations that the gaps would narrow over time and between generations, university graduation rates and earnings gaps within the second generation are no smaller than the gaps observed in the first generation, nor have these gaps been appreciably attenuated over time within members of the second generation (Mark 1996; Cohen and Haberfeld 1998).

Previous research identified several factors responsible for the failure of the second generation to close the ethnic gap in higher education, and hence in earnings. These includes individual factors, most notably parents' socioeconomic standing (Adler, Lewin Epstein and Shavit 2005) but also students' aspirations for occupations requiring higher education (Ayalon 1992). There are also structural factors, such as the lower quality of schools in peripheral towns 
(and poor neighborhoods in the cities) where the vast majority of students are Mizrahim. Equally important is the tracking system in high school education, that includes, in addition to the academic track leading to matriculation, a vocational track which practically prevents students from obtaining matriculation diploma (which is a prerequisite for university enrollment). Previous research reported that Mizrahim of the second generation not only were overrepresented in the vocational track (Shavit 1984), but at times were sent there due to statistical or institutional discrimination (Swirski 1999).

Little research has been conducted on the third generation, and even less on persons of mixed ethnicity. Two recent studies on the third generation (Dahan et al. 2002; Friedlander et al. 2002) limited their focus to gaps in educational levels, and especially to differences in high school matriculation (but not to university graduation). They reached conflicting conclusions. The results of Friedlander et al. (2002) suggest that in the third generation, Mizrahim completely closed the ethnic gaps in matriculation diplomas and entrance to academic education (but not graduation) with Ashkenazim. By contrast, Dahan et al. (2002) report no improvements in the ethnic gaps between second- and third-generation persons in obtaining matriculation diplomas. While Friedlander et al. (2002) did not study persons of mixed ethnicity, Dahan et al. (2002) found such persons to have higher matriculation rates than Mizrahim, but lower than Ashkenazim. Given the conflicting results regarding ethnic gaps in the third generation (to which we will later return), a new study is in order.

To be sure, high school matriculation diploma (the main educational measure of both studies) is still an important element in the Israeli educational system. However, since the early 1980s matriculation diploma by itself no longer guarantees entrance to a university, or 
acceptance to fields of studies leading to prestigious and high earnings occupations. ${ }^{3}$ Moreover, university applicants of 1980s did not benefit much from the recent reform in the higher education system that enabled dozens of new colleges to award first academic degrees (Ayalon and Yogev 2005). This being the case, university applicants in the 1980s -- the decade when the cohort of third generation Israelis studied in this paper reached university age - faced a rather homogenous system of higher education. With the exception of a minority of less than 10 percent of students (mostly women, more on this later) who attended teachers colleges, undergraduate students were enrolled in one of six public research universities, and were admitted according to the level and grades of their matriculation diploma, combined with their test scores in a state-wide, SAT-like psychometric test.

In the labor market, the critical certificate for success has increasingly become a university degree (B.A or its equivalent) rather than high school matriculation, or other, nonacademic post-secondary education. The economic returns of university degrees have increased sharply in the past three decades (Dahan 2001), and by 1995 the average earnings of Israeli-born, Jewish high-school graduates, 25-54 years of age, was only about two thirds of the average earnings of their university graduate counterparts (our analysis of the 1995 census). This being the case, the present study focuses on ethnic gaps in university graduation between Mizrahim and Ashkenazim of both the second and third generations, as well as between these two ethnic groups and the growing group of persons of mixed ethnic origin.

${ }^{3}$ Before 1980 matriculation diploma practically guaranteed admission to a university in most field of studies (Ayalon 2000). However, followed continuous reforms in matriculation exams in the 1980s and 1990s this is no longer the case. See Ayalon and Shavit (2004) for the effect of the reforms on the ethnic gap in attaining a matriculation diploma leading to university admission. 
The literature on interethnic marriages is extensive, mainly because such marriages are viewed, correctly, as the ultimate measure of social assimilation (Waters and Jimenez 2005). Most of this literature focuses the determinants and rates of such marriages. We focus on a related issue, namely, on the implication of such marriages on the educational attainment of children. Unfortunately, relatively little research has been conducted on this question - in part because of data availability, and in part because of the widespread belief that such marriages are of positive consequences for the offspring. Indeed, available evidence from the US suggest that second generation children of mixed marriages are doing educationally better than children where both parents are of the disadvantaged ethnicity (Perlmann 2005). We see no reason to expect the situation in Israel to be different.

\section{Data and Measures}

Our analyses are based on the matched 1983-1995 intergenerational census file that includes data for individuals (and their household members) who were in the 20 per cent demographic samples of both the 1983 and 1995 censuses. This special data set is a representative sample of approximately 4 per cent of the Israeli population in both census years (the probability of being included in both census samples), and it enables us to identify the ethnic origin of members of the second and third generations who resided in their parents' households in 1983. For thirdgeneration Jews (Israeli-born, to Israeli-born parents) who resided in their parents' households in 1983, it is possible to classify the respondent's ethnicity - Ashkenazi, Mizrahi, or someone of mixed ethnicity - according to the grandfather's country of birth (obtained from the 1983 records). 
Since the matched file includes this information only for persons residing in their parents' households in 1983, the sample of respondents over 34 years old in 1995 is relatively small, and is unlikely to be representative of all the Israeli-born over 34 years of age. Consequently, we limit the analyses to Israeli-born Jews, who were 25-34 years of age in 1995 and who resided with both parents in 1983 , when they were 13 to 22 years of age. ${ }^{4}$ The total sample size is 11,162 individuals of the second and third generations. Since most Jews in Israel serve in the military for two or three years between the ages of 18 and 21, during which they are considered to reside in their parents' households by the CBS, the fact that the sample includes only persons residing with their parents in 1983 is not a problem for its representativeness. We also compared the marginal distributions of some characteristics of our sample (education, occupation, and earnings) by age groups to the same characteristics among the Israeli-born of the same age groups, drawn from the 1995 census and the 1995 income survey, regardless of their place of residence in 1983. The differences between the matched file and the two other samples (not shown) are very small. It thus appears that the matched file is adequate for generalizing the results to the population of Israeli-born Jews, 25-34 years of age.

Figure 1 presents the most detailed classification possible for the ethnic origin of the sample members. It includes 24 cells, representing all possible combinations of parental continent of birth, and for parents born in Israel, their fathers' continent of birth as well. In addition to parental continent of birth, each cell includes the number of respondents. We classified the 24 combinations to three ethnic categories - Ashkenazim (on the right side), Mizrahim (on the left side), and mixed origin (in the middle) - based on the parents' and

\footnotetext{
${ }^{4}$ The results are unchanged if persons who resided with only one parent in 1983 are included in the analysis (and hence their ethnic origin is determined according to only one parent or grandparent).
} 
grandfathers' country of birth. Ashkenazim are those with at least one parent or grandparent who was born in Europe or America (E-A), and not even one parent or grandparent who was born in Asia or Africa. Similarly, Mizrahim are those with at least one parent or grandparent who was born in Asia or Africa (A-A), and none who was born in Europe or America; persons of mixed origin have at least one parent or grandparent of each ethnic origin. The 24 combinations are also classified by generation, according to parents' country of birth. Members of the second generation are defined as such if at least one of their parents was born abroad. ${ }^{5}$ Members of the third generation are defined as such if both their parents were born in Israel, and at least one grandparent was born abroad. ${ }^{6}$

$<$ Figure 1 about here $>$

This classification differs from most existing classifications (e.g. Cohen and Haberfeld 1998; Friedlander et al. 2002) as it relies on both parents, thereby allowing for mixed ethnic origin. Given the relatively high occurrence of interethnic marriage among Israeli Jews (Shavit and Stier 1997; Okun 2001), the proportion of persons of mixed origin, which is already appreciable (about 14 per cent of the sample), is expected to grow in the future. The proportion of third-generation Jews (about 13 per cent in the sample), as we will show later, is likely to increase even faster. Evidently, in the coming years the state of the ethnic cleavage among Israeli Jews will increasingly be determined by the socioeconomic achievements of members of the third generation and those of mixed ethnicity. The above classification enables us to analyze their socioeconomic achievements.

\footnotetext{
${ }^{5} \mathrm{We}$ also estimated some of the models separating members of the second generation, both of whose parents were born abroad, from those having one parent who was born abroad and one in Israel. The results were appreciably the same.

${ }^{6} \mathrm{We}$ excluded the few cases belonging to the fourth generation (both grandparents born in Israel). Their university graduation rates ( 25 per cent) are similar to those of mixed ethnicity.
} 
Our main measure of educational attainment is a dummy variable coded ' 1 ' if a respondent has at least a first university degree (usually B.A.). ${ }^{7}$ The independent variables for explaining differences in educational levels are respondent's age and parental characteristics drawn from the 1983 records, at the time respondents were living in their parents' households. These include father's and mother's years of schooling, a dummy variable for each parent coded ' 1 ' if they held at least a university first degree, number of children (i.e., respondent's number of siblings), father's and mother's occupation measured by dummy variables coded ' 1 ' if they held a professional technical or managerial (PTM) occupation, and (ln) family income.

\section{Descriptive Results}

Figure 2 presents the percentage of respondents with at least a university degree among the three ethnic groups by generation, age group, and gender. Not surprisingly, university graduation rates increase with age, reflecting the fact that a substantial share of Israeli students graduates from university in their late 20s and early 30s (Cohen and Haberfeld 1998). ${ }^{8}$ In addition, in both age groups, there are gender gaps. Women are more likely than men to be university graduates, and the gender gap widens in the third generation.

Turning to the ethnic gaps, which are the focus of our analysis, the results regarding the second generation confirm what we know from numerous previous studies: Ashkenazim are about three times as likely as Mizrahim to be university graduates. Specifically, 32 and 40 per cent of Ahskenazi men and women are university graduates, compared to 10 and 13 per cent

${ }^{7}$ The results are appreciably the same when 'years of schooling' is the educational measure (Appendix A).

${ }^{8}$ The proportions of those 25-29 years of age with less than a B.A. degree, who were still studying towards their B.A degree in 1995 and are thus expected to have graduated in the late 1990s, are appreciably higher among Ashkenazim (25 per cent) than among Mizrahim (14 per cent), and the results do not differ by generation. 
among Mizrahi men and women, respectively. University graduation levels among thirdgeneration men are about the same (33 per cent among Ashkenazim and 9 among Mizrahim), while among women the rates increased appreciably in the third generation (50 per cent among Ashkenazim and 18 per cent among Mizrahim). The outstanding question, however, is whether the ethnic gaps have narrowed appreciably over the generations. Clearly, the answer to this question is negative. The ethnic gaps in university graduation rates among men and women of the third generation are about as wide as the gaps in the second generation: an absolute difference of 23-24 percentage points among men, and, 27-31 points among women.

$<$ Figure 2 about here $>$

Persons of mixed ethnicity are located about midway between the two ethnic groups. This finding is robust. It is observed in both age groups, and in both genders and both generations. Moreover, the same pattern of results is evidenced when the measure of educational attainment used is mean years of schooling (see Appendix A) rather than the percentage of university graduates. The difference between the ethnic groups is not limited to average educational levels. It is also observed in the variance within the groups. Both Ashkenazim and Mizrahim are more homogeneous with respect to their educational attainments than persons of mixed ethnicity (data not shown).

In sum, Figure 2 suggests that the ethnic hierarchy in Israel is rather rigid and does not change much from generation to generation. That persons of mixed ethnicity are consistently located between the two major Jewish ethnic groups is perhaps another indication of the rigidity of the ethnic-based hierarchy among Israeli Jews, where Ashkenazim are at the top, followed by persons who are only partly Ashkenazi, and those with no Ashkenazi ancestry are at the bottom. However, since university graduation rates of persons of mixed ethnicity are almost twice as 
high as the rates among Mizrahim, the relative size of this group appears to be the key to mitigating ethnic-based stratification in Israel. Below we provide estimates of the relative size of the three ethnic groups of the second and third generations in the near future.

Figure 3 presents the distribution of the three ethnic groups for persons 12-34 years of age in 1995, by age groups and generation. ${ }^{9}$ Ashkenazim (of both generations) account for about one-third of the Israeli-born in all age groups, while the proportion of Mizrahim declines from 57 to 49 per cent between the older and youngest cohorts. This being the case, the proportion of persons of mixed ethnicity, which is about 12 per cent among the Israeli-born of the oldest age group, increases to about 17 per cent among the youngest age group. The proportion of thirdgeneration Israeli Jews (of the three ethnic groups) has increased from about 9 per cent of the oldest group to about 41 per cent among the youngest age group. Specifically, in 1995 thirdgeneration Israelis are about one-half of Israeli-born Ashkenazim, and about one-third of both Israeli-born Mizrahim and persons of mixed ethnicity, 12-14 years of age. The respective proportions of third-generation Israelis among persons 30-34 years old in 1995 are about onefifth among Ashkenazim, 3 per cent among Mizrahim, and 9 per cent among persons of mixed ethnicity. Evidently, the fastest growing group among Israeli-born Jews, at least until 1983, is third-generation Israelis, irrespective of their ethnicity, rather than those of mixed ethnicity.

$<$ Figure 3 about here $>$

These changes do not bode well for the attenuation of the ethnic gap in the coming years. Since ethnic gaps in university graduation rates are as high in the third generation as in the second generation, the sharp increase in the proportion of the third generation among Mizrahim and Ashkenazim of the youngest age groups is not likely to appreciably narrow the gaps in

${ }^{9}$ The matched file includes information on all the children who resided in their parents' households in 1983, hence the youngest children in 1995 are 12 years old. 
educational attainment between the two ethnic groups when they reach university graduation age. Likewise, the popular belief that in the near future the majority of Israeli-born adults will be persons of mixed ethnicity is not supported by the data. Rather, by 2010,5 of every 10 Israeliborn, 27-29 years of age (12-14 in 1995), will be (low education) Mizrahim, 3 will be (high education) Ashkenazim, and only 2 will be persons of mixed ethnicity, with relatively high educational levels, but not as high as that of Ashkenazim. ${ }^{10}$ Taking into consideration the educational level of new immigrants arriving Israel in the past two decades, the ethnic cleavage in education is likely to be even more pronounced. Specifically, since 1983 Israel received nearly 100,000 low-education Mizrahi immigrants from Ethiopia (including their Israeli born offspring), and (especially since 1989) over one million highly educated Ashkenazi immigrants (and their Israeli-born offspring) from the former Soviet Union.

\section{Multivariate analysis}

In Israel, as in other countries, children's educational attainment is known to be affected by parental characteristics (Shavit and Pierce 1991; Dahan et al. 2002; Friedlander et al. 2002). The primary question we would like to answer in this section is whether persons of Mizrahi and mixed ethnic origin are less likely to be university graduates than Ashkenazim of similar measured parental characteristics. To this end we have estimated logistic regressions where the dependent variable is whether respondents have at least a university first degree. The independent variables are the respondents' age and number of siblings, parental characteristics (father's and mother's education and occupation as well as family income), and the six

${ }^{10}$ This conclusion, however, is limited to those born before 1983. Since the proportion of ethnically intermarried couples increased from about 14 per cent in the 1950 s and early 1960 s to about 28 per cent in the early 1990s (Okun 2001), the proportion of persons of mixed ethnicity is likely to be higher among those born in the late 1980s and 1990s. 
combinations of ethnic origin and generation: second-generation Ashkenazim (the benchmark group, omitted from all regressions), second-generation Mizrahim, third-generation Mizrahim, second-generation mixed, third-generation mixed, and third-generation Ashkenazim.

$<$ Table 1 about here $>$

Columns 1-3 of Table 1 present the results for the entire sample. Evidently, parental background has a large effect on the probabilities of university graduation among children. Specifically, the higher the father's and mother's education, occupation and income, and the lower the number of siblings, the more likely the children are to be university graduates. These effects of parental background are consistent with the results of previous research in Israel and in other countries.

The effects of ethnicity, however, are still considerable and statistically significant among persons of the same age and parental educational level (column 2). These effects do not diminish much when parental occupation and income are also held constant (column 3). Indeed, the probabilities of obtaining a university degree increase along the ethnic hierarchy in the expected direction, from Mizrahim, through persons of mixed ethnicity, to Ashkenazim. The odds of second- and third-generation Mizrahim being university graduates are only 0.563 and 0.485 , respectively, relative to the benchmark group - second-generation Ashkenazim of equal measured characteristics (column 3$)$. The odds for persons of mixed ethnicity are higher $(0.744$ for the second generation and not significantly different from 1.0 for the third generation), while the odds of third-generation Ashkenazim being university graduates are similar to those of their second-generation counterparts.

The results, however, differ by gender. Among men, Mizrahi ethnicity depresses university graduation rates in the third generation no less than in the second generation (column 
6). Among women, by contrast, the direct effect of ethnicity on education has declined substantially in the third generation (column 9). Consequently, the claim that ethnicity plays no role in university graduation in the third generation can be rejected, although the effect is weaker among women than among men. Two processes might explain, at least in part, this gender-based difference among third-generation Mizrahim. First, as shown in Figure 2, the proportion of third generation Mizrahi women who are university graduates is relatively high. This, however, is in part because a disproportionate share of Mizrahi women graduated from teachers' colleges while (university-graduate) Ashkenazi men and women, as well as second generation Mizrahi women graduated from Israel's major universities. Specifically, 10 and 12 per cent, respectively, of second-generation Ashkenazi and Mizrahi women with academic degrees are elementary school teachers who most likely graduated from teachers colleges (data not shown). ${ }^{11}$ In the third generation the respective proportion among Ashkenazi women dropped to 7 per cent, while it remained appreciably the same (13 per cent) among Mizrahi women (only about 1 per cent of Mizrahi and Ashkenazi men of either generation graduated from teachers' colleges). Hence, the relative success of third-generation Mizrahi women to hold academic degrees is in part due to the rise in the proportion of them who graduated from teachers' colleges. The second process that may be the explanation for the relative success of third-generation Mizrahi women is that the ethnic gap in high school track (vocational vs. academic) is smaller among women than among men (Adler et al. 2005).

The results regarding persons of mixed origin are also gender-specific. Among women of the same family background, persons of mixed ethnicity of both the second and third generations

${ }^{11}$ The census makes no distinction between teachers' colleges and other institutions of higher education. However, since most elementary school-teachers are graduates of teachers' colleges, we can use this occupation as a proxy for attending a teacher's college rather than a university. 
are as likely as Ashkenazim to be university graduates (column 9). Among men, however, only the third generation has achieved parity with Ashkenazim, while the chances that persons of mixed origin of the second generation shall be university graduates are no greater than those of second generation Mizrahim (column 6).

\section{Discussion and Conclusions}

The results reported in this paper lead to an unequivocal conclusion: in Israel the educational gaps among the third generation are as large as among the second generation, while persons of mixed ethnicity increasingly become more similar to Ashkenazim. The first part of this conclusion - that the gaps between Mizrahim and Ashkenazim are as large in the third generation as in the second generation - differs from the results reported by Friedlander et al. (2002 p. 143; 2004 p. 126) for the same age group of third-generation Israelis (25-34) in 1995. There are some important differences between our study and Friedlander's, especially with respect to the data sources, definition of ethnic categories (three in our study vs. two in Friedlander's study) and educational measures (completion in our study vs. entry to academic education in Friedlander's), which potentially could explain the different results regarding the third generation.

We wish to stress, however, that our results are consistent with the results of Dahan et al. (2002), which are based on a more reliable data set and larger sample size than used by either Friedlander et al. (2002) or ourselves. Both Friedlander et al. (2002) and we relied on data sources consisting of records from two censuses that were matched by the Israeli CBS (and in the case of Friedlander et al. by the ministry of interior as well) and are thus subject to nonnegligible errors in the matching process. By contrast, the findings of Dahan et al. (2002) are 
based on a simpler and larger data set (the 20 percent 1995 census, including some 12,000 thirdgeneration Israeli-born) that required no matching, and thus the likelihood of errors is lower. ${ }^{12}$ Thus, to the extent that the findings of Dahan et al. (2002) are correct - namely, that the gaps in high school matriculation in the third generation are as large as in the second generation - it is all the more likely that ethnic gaps in university graduation rates are also as large in the third generation as in the second, for in Israel a matriculation diploma is a prerequisite for entry to academic education.

To be sure, much of the advantage of Ashkenazim is rooted in their more advantageous family backgrounds. But this cannot be the only explanation for the failure of Mizrahim to reach the same university graduation rates as Ashkenazim. Even among persons of similar family background, whose parents have the same educational level, occupation and income, with the same number of siblings, the ethnic ratios in university graduation rates (Mizrahim to Ashkenazim) are still substantial: about two-to-three among the second generation, while the results of the third generation differ by gender: about one-to-two among women, but one-to-three among men. Evidently, in the third generation ethnicity is more important for men's educational attainment than for women's. In fact, among men, third-generation Mizrahim are doing worse than second-generation Mizrahim of the same measured family background. ${ }^{13}$

${ }^{12}$ Dahan et al. (2002) focused on high-school matriculation rates among young adults, aged 1821 in 1995, who lived in their parents' households in that year. Hence, the parents' and grandparents' country of birth were obtained from the parents' records. Evidently, this data set is inappropriate for estimating university graduation rates among older persons (25-34, the age group used by both Friedlander et al. [2002] and ourselves) because most persons of this age group do not reside in their parents' households.

${ }^{13}$ We checked for gender differences in the country of birth of grandfathers of third-generation Mizrahim. The results suggest that about one third of the grandfathers of third-generation Mizrahim were born in Yemen, reflecting the composition of Mizrahim in the Jewish society of Mandatory Palestine. However, since this pattern was found among both gender groups, 
Several factors are responsible for the fact that in Israel the ethnic gaps in higher education have not been substantially narrowed in the third generation. One reason discussed and tested in this paper is parental characteristics. Given Israel's policy regarding university admission - practically complete reliance on state-wide matriculation exams and scores in a psychometric test - it is not surprising that parental resources were found to affect university graduation. Well-to-do families have the financial ability to send their children to special preparatory courses for the psychometric tests, as well as to finance extra tutoring during their school years. In addition to the financial and educational resources of parents, it is possible that there are cultural differences between Mizrahi and Ashkenazi families in their "taste" for higher education and the value they put on it. While there are no readily available data on such differences, one study found that Ashkenazi families (mostly second generation) save a higher proportion of their income than Mizrahi families of the same income, education and family size, concluding that this difference in spending patterns is suggestive of Ashkenazi and Mizrahi preferences "with all known implications for future investment in human capital and the size of future [emphasis added] gaps" (Mark 1994, p. 65).

Other factors, structural in nature, also contributed to the persisting gaps between the two ethnic groups. For one thing, the tracking system in Israel's educational system, which channels a disproportionate number of Mizrahim (especially men) to the vocational track, has been affecting Mizrahim regardless of their generation throughout the 1970s and early 1980s (the period when our sample members attended high-school) (Shavit 1984). For another thing, even Mizrahim attending the academic track in high-school suffer from lower quality schools and a narrower curriculum than their Ashkenazi counterparts. As late as 1989 Mizrahi students were

Yemenite origin cannot be invoked to explain the lower educational achievements of thirdgeneration Mizrahi men. 
unable to take core subjects at their highest levels due to lack of course offering in Mizrahidominated schools in poor neighborhoods (Ayalon 1994).

In sum, many of the structural factors that were found to be responsible for the gaps in the second generation appear to be responsible for the gaps in the third generation, too. This is understandable, given that we studied an early cohort of the third generation, those born between 1961 and 1970. Most likely, these members of the third generation were subject to the same structural factors affecting their same-age counterparts of the second generation. It is likely that what happened to this early cohort of third-generation Israelis, whose parents, for the most part, were born in Israel before 1948, is all the more suggestive of what would happen to later cohorts of third-generation Israelis, those born in the 1970s, 1980s, and 1990s, whose parents were born in the throes of the great adjustments after statehood in 1948, with all its adverse implications for Mizrahi immigrants.

Most European and Asian immigrant groups in the US closed, or substantially narrowed, the educational gaps with natives within two or three generations (Alba 1990). As we have seen, this has not been the case in Israel. What, then, may explain the difference between the Israeli and American experience with respect to the educational assimilation of the third generation? The answer, we believe, has to do with what Waters and Jimenez (2005) call "immigrant replenishment". The US findings of complete assimilation in three generations are based on the descendents of European immigrants arriving at the turn of the $20^{\text {th }}$ century. In that case, there was no protracted immigrant replenishment, almost no overlapping between birth cohorts and generations, and each successive generation had less contact with the immigrant generation (Waters and Jimenez 2005). In the Israeli case, however, where Ashkenazi and especially Mizrahi immigration intensified in the 25 years after 1948, members of the third generation were 
connected to the immigrant generation and the immigration experience in many respects. Protracted (Mizrahi) immigrant replenishment and the experience of the Mizrahi second generation maintained the ethnic cleavage in Israeli society across birth cohorts and generations. In their own eyes as well as in the eyes of relevant actors - state agencies, educational professionals, employers and the public at large - these young members of the third generation were most likely indistinguishable from their same-age counterparts of the second generation.

In Israel, as in other countries, university graduation is the main determinant of occupational status and earnings. Consequently, our results suggest that the ethnic cleavage is unlikely to disappear among members of the third generation. Rather, the ethnic-based educational gaps among those 25-34 years of age in 1995 have already produced earnings gaps that are similar to the gaps among second-generation Israelis (Appendix B). These ethnic-based earnings gaps are likely to widen as members of the third generation gain labor market experience. Moreover, educational differences among the youngest members of the third generation (12-14 in 1995) are likely to develop by 2010, when they will be 27-29 years of age. If this indeed occurs, ethnic differences in earnings will last at least until this cohort exits the labor market, sometime between 2040 and 2050.

To be sure, these projections are based on the assumption that the gaps in university graduation rates of future birth cohorts of the third generation will remain appreciably stable. Although this assumption has proved correct in the past - gaps in university graduation between successive cohorts of second-generation Israelis did not narrow much between 1975 and 1995 this may not be the case with the third generation. Recent developments in Israel's higher education system may help younger and future cohorts of third-generation Mizrahim to narrow the higher education gap with their Ashkenazi counterparts. Specifically, the establishment of 
new private, and especially public, colleges in peripheral areas enables a greater proportion of Israelis to obtain higher education. Indeed, there is evidence that the proportion of Mizrahim in these newly created, albeit lower-status, colleges is higher than their share in Israel's major universities (Aaylon and Yogev 2005).

Unfortunately, there are no readily available data on the economic returns of the degrees obtained in such colleges. A reasonable assumption is that in the coming years distinctions between types of colleges and universities will be established and institutionalized, and a disproportionate number of Mizrahim will graduate from colleges and majors leading to lower earnings. This pattern has already begun among Mizrahi women of the third generation, who tend to flock in increasing numbers to teachers' colleges, while their Ashkenazi counterparts attend major universities. Given the relatively low wages of graduates of teachers' colleges (who are mostly elementary school-teachers), ethnic differences in earnings among women of the third generation are expected to be no less than among men.

Although differences between Mizrahim and Ashkenazim of either generation may not significantly narrow over time, one aim of the Israeli melting pot has been to reduce the proportion of these two ethnic groups and supplant them with persons of mixed ethnicity (of unequivocal 'Israeli origin,' to use the CBS terminology), of relatively high educational levels. This has indeed occurred to some extent, but not fast enough to diminish the ethnic-based stratification system within three generations. Yet the results of this study suggest that diminishing the ethnic gaps in Israeli society depends more on the rates of interethnic marriages than on educational reforms, which have proven in the past to be ineffective in closing the gaps between the two ethnic groups. 


\section{References}

ADLER, IRIT., LEWIN-EPSTEIN, NOAH and SHAVIT, YOSSI 2005 'Ethnic stratification and place of residence in Israel: a truism revisited', Research in Social Stratification and Mobility, vol. 23, pp. 155-190

ALBA, RICHARD 1990 Ethnic identity: the transformation of white America, New Haven: Yale University Press.

AYALON, HANNA 1992 'School tracking and gender differences in occupational aspiration: economic aspects', in Abraham Yogev (ed), International Perspectives on Education and Society, vol. 2, Greenwich, CT: JAI Press, pp. 259-275

--- 1994 'Monopolizing knowledge? The ethnic composition and curriculum of Israeli high schools', Sociology of Education vol. 67, no 4, pp. 264-278

--- 2000 'The reform in the structure of studies in the upper division of Israeli high schools', in Hanna Herzog (ed.) Reflection of a society: in memory of Yonathan Shapiro, Tel Aviv: Ramot. (Hebrew), pp. 125-146.

--- and SHAVIT, YOSSI 2004 'Educational reforms and inequalities in Israel', Sociology of Education vol. 77, no. 2, pp. 103-120

AYALON, HANNA and YOGEV, AVARAHAM 2005. 'Field of Study and Students Stratification in an Expanded System of Higher Education: The Case of Israel', European Sociological Review, vol. 21, no. 3, pp. 227-241

BEN RAFAEL, ELIEZER 1982 The Emergence of Ethnicity: Cultural Groups and Social Conflict in Israel, Westport, CT: Greenwood Press

BOYD, MONICA, FEATHERMAN, DAVID and MATRAS, JUDAH 1980 'Status attainment of immigrant and immigrant origin categories in the US, Canada, and Israel', Comparative Social Research, vol. 3, pp. 199-228

CHISWICK, BARRY 1978 'The effects of Americanization on the earnings of foreignborn men', Journal of Political Economy vol. 86, no. 5, pp. 897-921

COHEN, YINON 2002 'From haven to heaven: changes in immigration patterns to Israel', in Danny Levy and Yifaat Weiss (eds), Citizenship and Identity: Germany and Israel in Comparative Perspective, New York: Berghahn Books, pp. 36-56

--- and HABERFELD, YITCHAK 1998 'Second generation Jewish immigrants in Israel: have the ethnic gaps in schooling and earnings declined'? Ethnic and Racial Studies, vol. 21, no 3, pp. 507-528 
DAHAN, MOMI 2001 'The rise in economic inequality', in Avi Ben Bassat (ed.), The Israeli Economy, 1985-1998: From Government Intervention to Market Economics, TelAviv: Am Oved Publishers, pp. 610-656 (Hebrew)

DAHAN, MOMI, MIRONICHEV NATALIA, DVIR EYAL and SHYE, SHMUEL 2002 'Have the educational gaps narrowed'? Economic Quarterly vol. 49, no, 1, pp. 159-188 (Heberw)

FRIEDLANDER, DOV, OKUN, BARBARY, EISENBACH, ZVI and ELMAKIAS, LILACH 2002 'Immigration, social change, and assimilation: educational attainment among birth cohorts of Jewish ethnic groups in Israel', Population Studies, vol. 56, no. 2 , pp. $135-150$

--- 2004 'Erratum' Population Studies, vol. 58, no. 1, pp. 125-126

GORDON, MILTON, M 1964 Assimilation in American Life: the Role of Race, Religion and National Origin, New York, NY: Oxford University Press.

KHAZZOOM, AZZIZA 2003 'The great chain of Orientalism: Jewish Identity, Stigma Management and Ethnic Exclusion in Israel', American Sociological Review vol. 68, no. 4, pp. $481-510$

MARK, NILI 1994 'Ethnic gaps in earnings and consumption in Israel', Economic Quarterly, vol. 41, no. 1, pp. 55-77 (Hebrew)

--- 1996 'The contribution of education to earnings differentials among ethnic groups in Israel', Israel Social Science Research vol. 11, no. 1, pp. 47-86

NAHON, YAAKOV 1987 Education Levels and Employment Opportunities: The Ethnic Dimension, Jerusalem: Jerusalem Institute for the Study of Israel (Hebrew).

OKUN, BARBARA 2001 'The effects of ethnicity and educational attainment on Jewish marriage patterns: changes in Israel, 1957-1995', Population Studies vol. 55, no. 1, pp. 49-64

PERLMANN, JOEL 2005 Italians then, Mexicans now: Immigrant Origins and SecondGeneration Progress, 1890-2000, New York: Russell Sage Foundation

PERES, YOCHANAN 1971 'Ethnic relations in Israel', American Journal of Sociology, vol. 76, no. 5, pp. 1021-1047

SEMYONOV, MOSHE and LERRENTHAL, TAMAR 1991 'Country of origin, gender, and the attainment of economic status: a study of stratification in the Jewish population in Israel', Research in Social Stratification and Mobility, vol. 10, pp. 325-343

SHAVIT, YOSSI 1984 'Tracking and ethnicity in Israeli secondary education', American Sociological Review vol. 49, no. 2, pp. 210-220 
SHAVIT, YOSSI. and PIERCE, JENNIFER, L. 1991 'Sibship size and educational attainment in nuclear and extended families: Arabs and Jews in Israel', American Sociological Review, vol. 56, no. 3, pp. 321-330.

SHAVIT, YOSSI and STIER, HAYA 1997 'Ethnicity and education in patterns of marriage in Israel: changes over time', Megamot vol. 38, no. 2, pp. 207-225 (Hebrew)

SMOOHA, SAMMY 1978 Israel, Pluralism, and Conflict, Berkeley: U.C. Press

SMOOHA, SAMMY and KRAUS,VERED 1985 'Ethnicity as a factor in status attainment in Israel', Research in Social Stratification and Mobility vol. 4, pp. 151-175

SPILERMAN, SEYMOUR, and HABIB, JACK 1976 'Development towns in Israel: the role of community in creating ethnic disparities in labor force characteristics', American Journal of Sociology, vol. 81, no. 4, pp. 781-812

SWIRSKI, SHLOMO 1999 Politics and education in Israel, NY: Falmer Press

WATERS, MARY AND JIMENEZ, TOMAS 2005 'Assessing immigrant assimilation: new empirical and theoretical challenges', Annual Review of Sociology, vol. 31, pp. 101125 .

YAAR, EPHRAIM 2005 'Continuity and change in Israeli society: a test of the melting pot', Israel Studies, vol. 10,no 2, pp. 91-128

YAISH, MEIR 2001 'Class Structure in A Deeply Divided Society. Class and Ethnic Inequality in Israel', British Journal of Sociology vol. 52, no. 3 pp. 409-439 
Table 1. Odds ratios from logistic regressions of the probabilities of attaining at least a B.A. degree: second- and third-generation Jews, 25-34 years old, 1995.

\begin{tabular}{|c|c|c|c|c|c|c|c|c|c|}
\hline & All & All & All & Men & Men & Men & Women & Women & Women \\
\hline & 1 & 2 & 3 & 4 & 5 & 6 & 7 & 8 & 9 \\
\hline \multicolumn{10}{|l|}{ Ethnic origin $^{a}$} \\
\hline II gen. Mizrahim & $0.226 * * *$ & $0.551 * * *$ & $0.563 * * *$ & $0.225 * * *$ & $0.573 * * *$ & $0.568 * * *$ & $0.221 * * *$ & $0.550 * * *$ & $0.582 * * *$ \\
\hline III gen. Mizrahim & $0.277 * * *$ & $0.456 * * *$ & $0.485 * * *$ & $0.202 * * *$ & $0.337 * * *$ & $0.343 * * *$ & $0.336 * * *$ & $0.565 * *$ & $0.639 *$ \\
\hline II gen. mix & $0.566 * * *$ & $0.752 * * *$ & $0.744 * * *$ & $0.439 * * *$ & $0.582 * * *$ & $0.574 * * *$ & $0.692 * * *$ & 0.945 & 0.958 \\
\hline III gen. mix. & 0.785 & 0.920 & 0.816 & 0.802 & 1.027 & 0.937 & 0.731 & 0.881 & 0.761 \\
\hline III gen. Ashk & $1.267 * * *$ & 0.911 & 0.950 & 1.029 & $0.790 *$ & 0.825 & $1.488 * * *$ & 1.055 & 1.127 \\
\hline \multicolumn{10}{|l|}{ Parental chars: } \\
\hline Father's B.A. & & $1.525 * * *$ & $1.316^{* * *}$ & & $1.570 * * *$ & $1.397 * *$ & & $1.516 * * *$ & 1.254 \\
\hline Mother's B.A & & $1.242 * *$ & 1.152 & & 1.028 & 1.058 & & $1.484 * * *$ & 1.239 \\
\hline Father's yrs of educ. & & $1.072 * * *$ & $1.065 * * *$ & & $1.071 * * *$ & $1.059 * * *$ & & $1.076 * * *$ & $1.075 * * *$ \\
\hline Mother's yrs of edu. & & $1.123 * * *$ & $1.112 * * *$ & & $1.132 * * *$ & $1.115 * * *$ & & $1.118 * * *$ & $1.111 * * *$ \\
\hline Age & & $1.094 * * *$ & $1.099 * * *$ & & $1.146 * * *$ & $1.150 * * *$ & & $1.044 * * *$ & $1.047 * * *$ \\
\hline Men & & $0.640 * * *$ & $0.652 * * *$ & & & & & & \\
\hline N. of siblings & & $0.994 * * *$ & $0.993 * * *$ & & $0.995 * *$ & $0.995^{*}$ & & $0.994 * * *$ & $0.992 * *$ \\
\hline Father in PTM $^{b}$ & & & $1.244 * * *$ & & & 1.046 & & & $1.463 * * *$ \\
\hline Mother in $\mathrm{PTM}^{\mathrm{b}}$ & & & 1.090 & & & 1.042 & & & 1.139 \\
\hline Family income & & & $1.234 * * *$ & & & $1.389 * * *$ & & & $1.121 * *$ \\
\hline $\begin{array}{l}-2 \text { log likelihood } \\
\text { Chi-square }\end{array}$ & 10,460 & 9,607 & 7,019 & 4,883 & 4,500 & 3,300 & 5,482 & 5,061 & 3,675 \\
\hline No. of Cases & 11,162 & 11,162 & 7,917 & 5,672 & 5,672 & 3,984 & 5,490 & 5,490 & 3,933 \\
\hline
\end{tabular}

${ }^{\mathrm{a}}$ Omitted category: II generation Ashkenazim
${ }^{\mathrm{b}}$ The omitted category include parents in occupations other than professional, technical and managerial, as well as those not in the labor force. We have also estimated these models excluding persons out of the58 labor force, and the results (not shown) were appreciably the same.

* $\quad \mathrm{P}<.10$

$* * \quad \mathrm{P}<.05$

$* * * \quad \mathrm{P}<01$ 
Figure 1. Second- and third-generation Israeli born Jews, 25-34 years old in 1995, by parents' and grandparents' continent of birth.

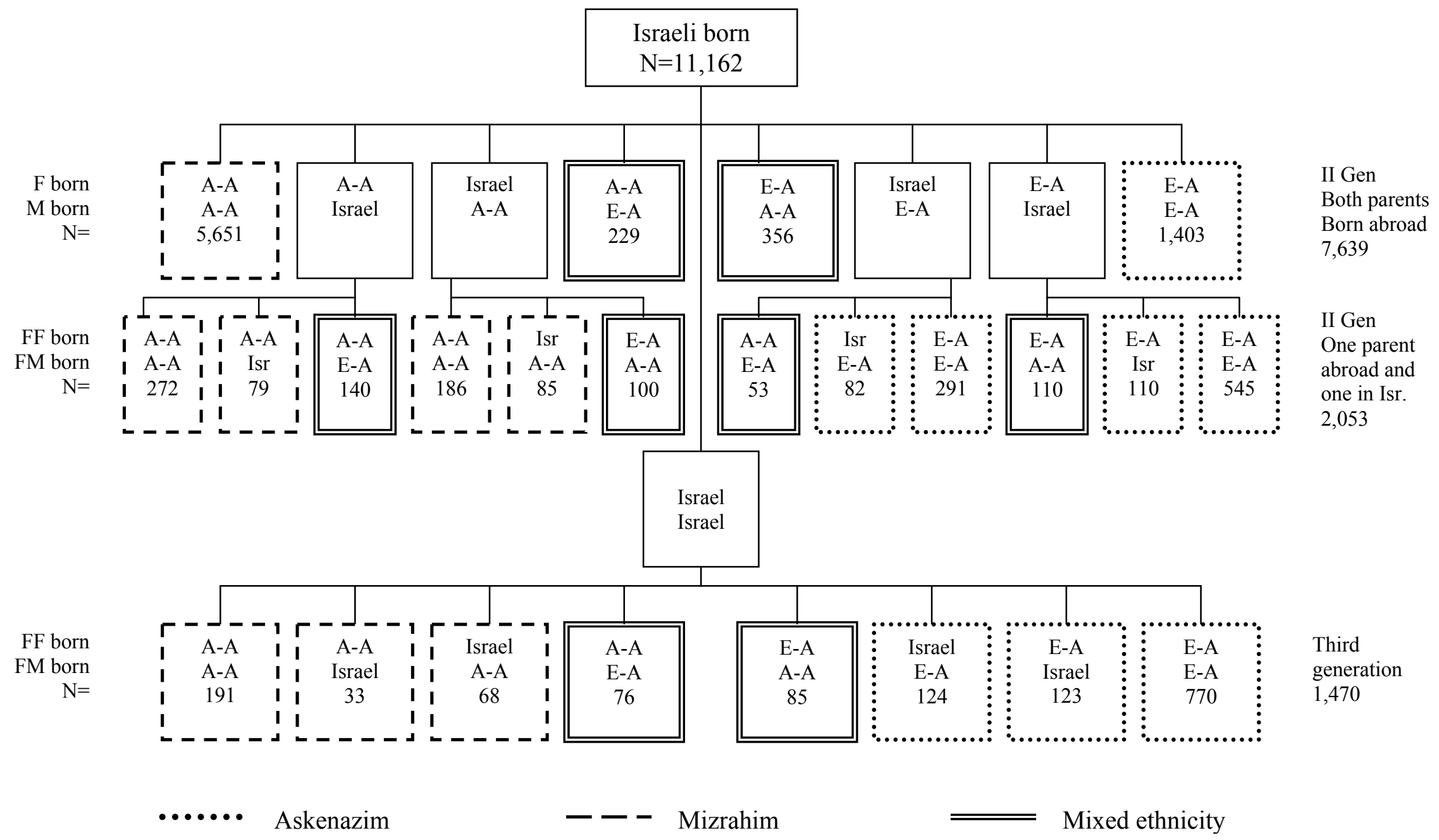


Figure 2. Percent with at least a College Degree: Israeli-born Jews by gender, age, ethnicity, and generation

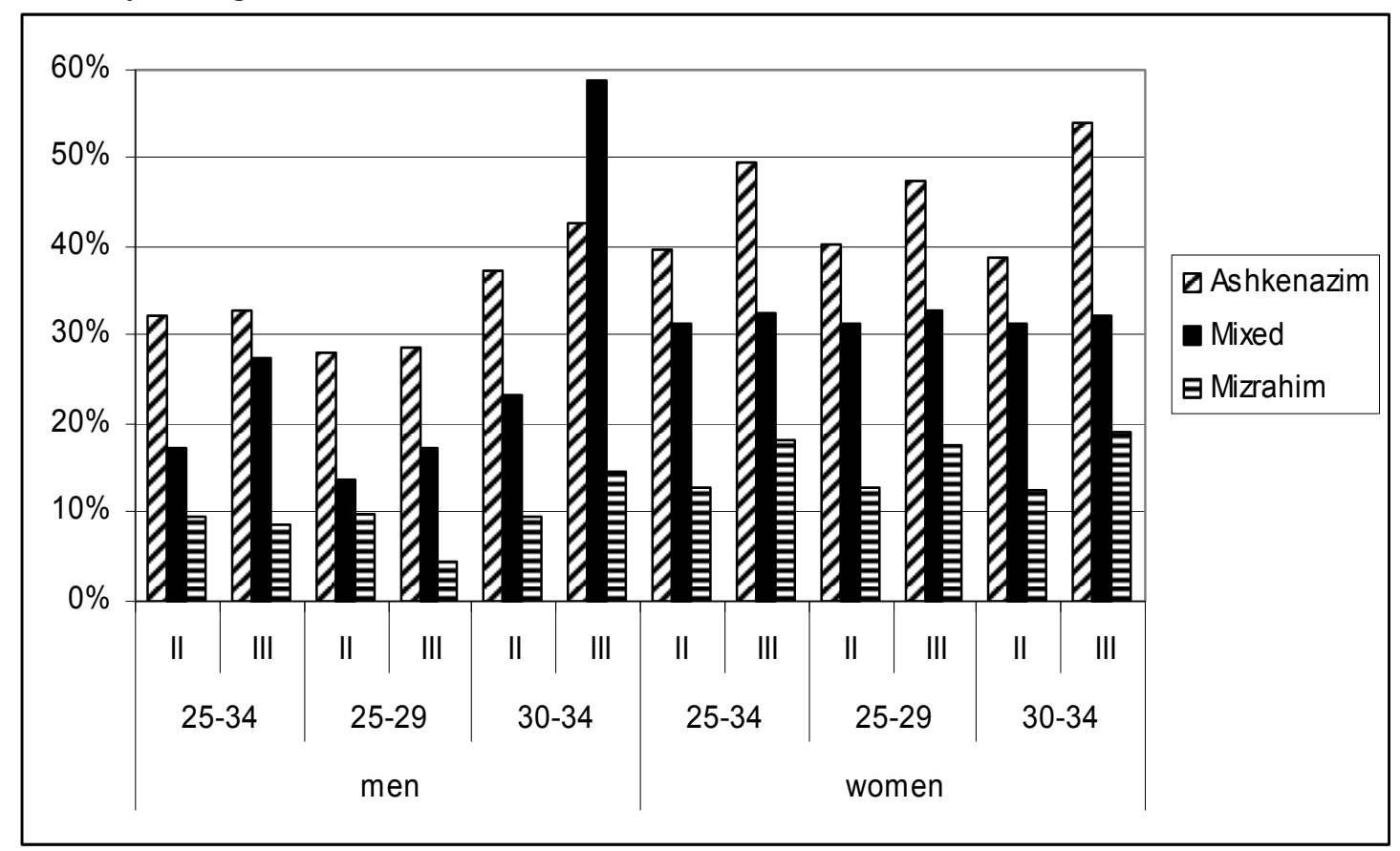

Number of observations for third-generation persons of mixed origin, 30-34 years old, is less than 30 in each gender group. 
Figure 3. Relative size of ethnic groups by age and generations: Israeli-born Jews, 12-34 years old.

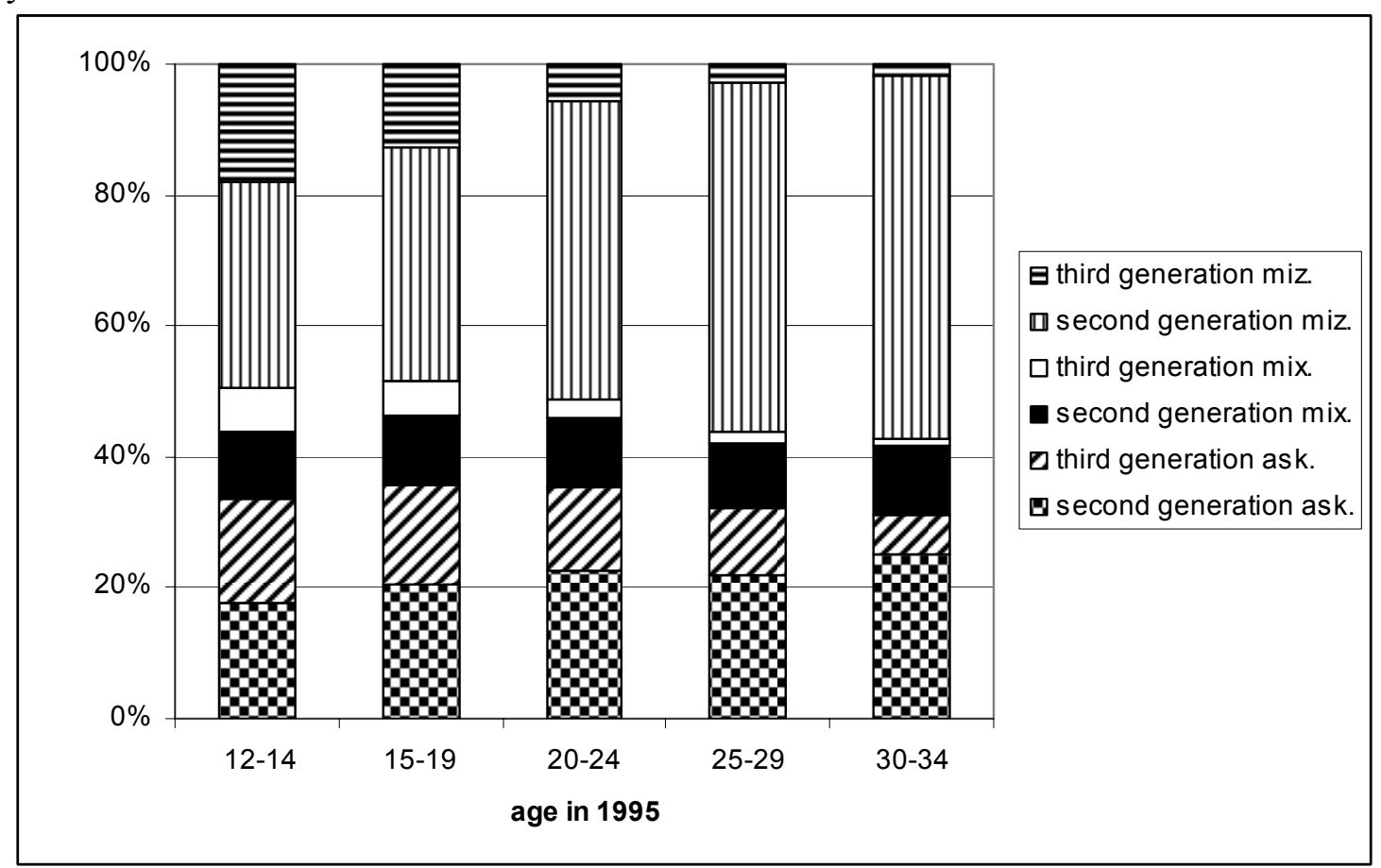


Appendix A: Mean years of schooling: Israeli-born Jews by gender, age, ethnicity and generation

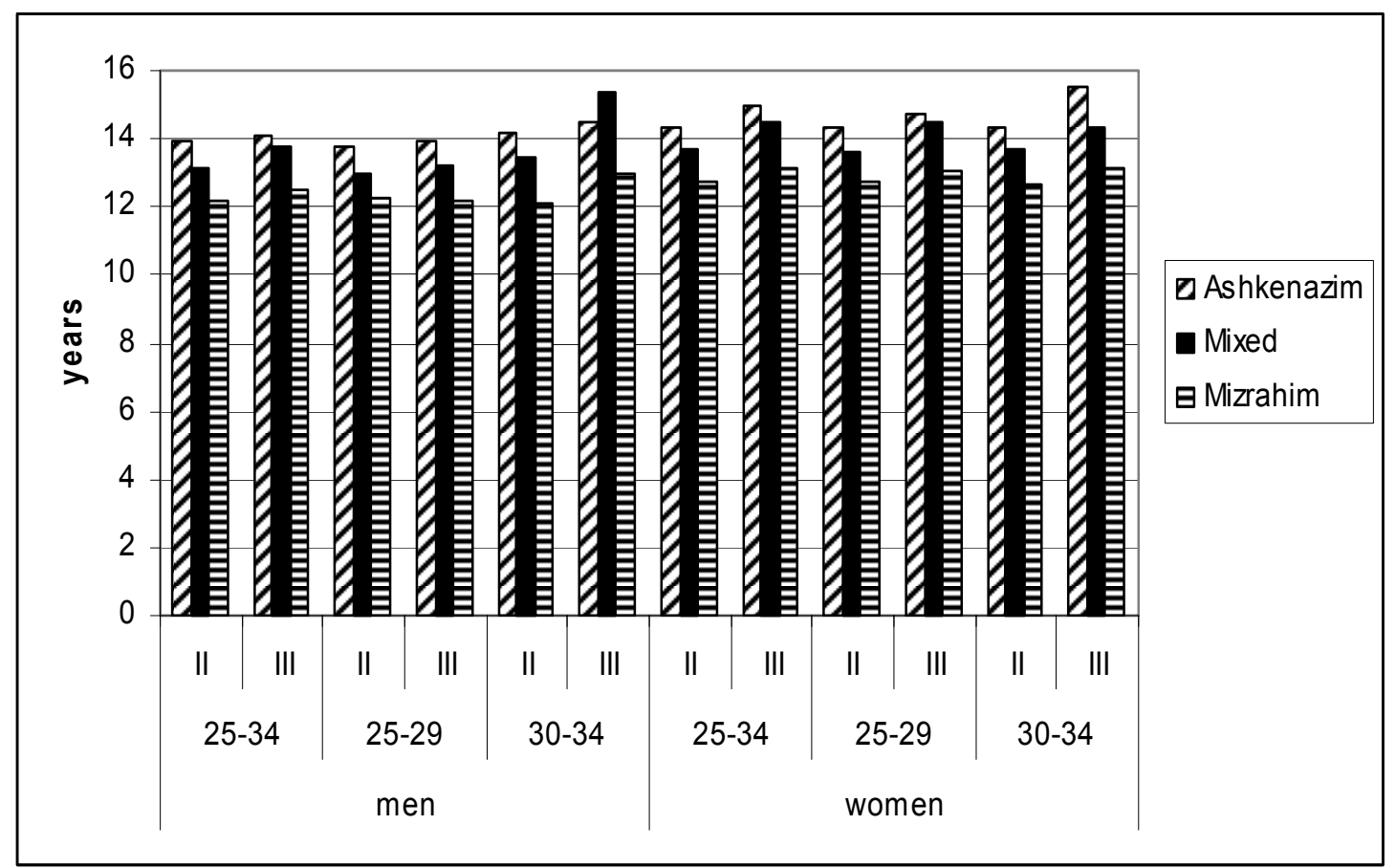

Number of observations for third-generation persons of mixed origin, 30-34 years old, is less than 30 in each gender group. 
Appendix B. Mean monthly earnings: Israeli-born Jews, 25-34 years old by gender, ethnicity and generation

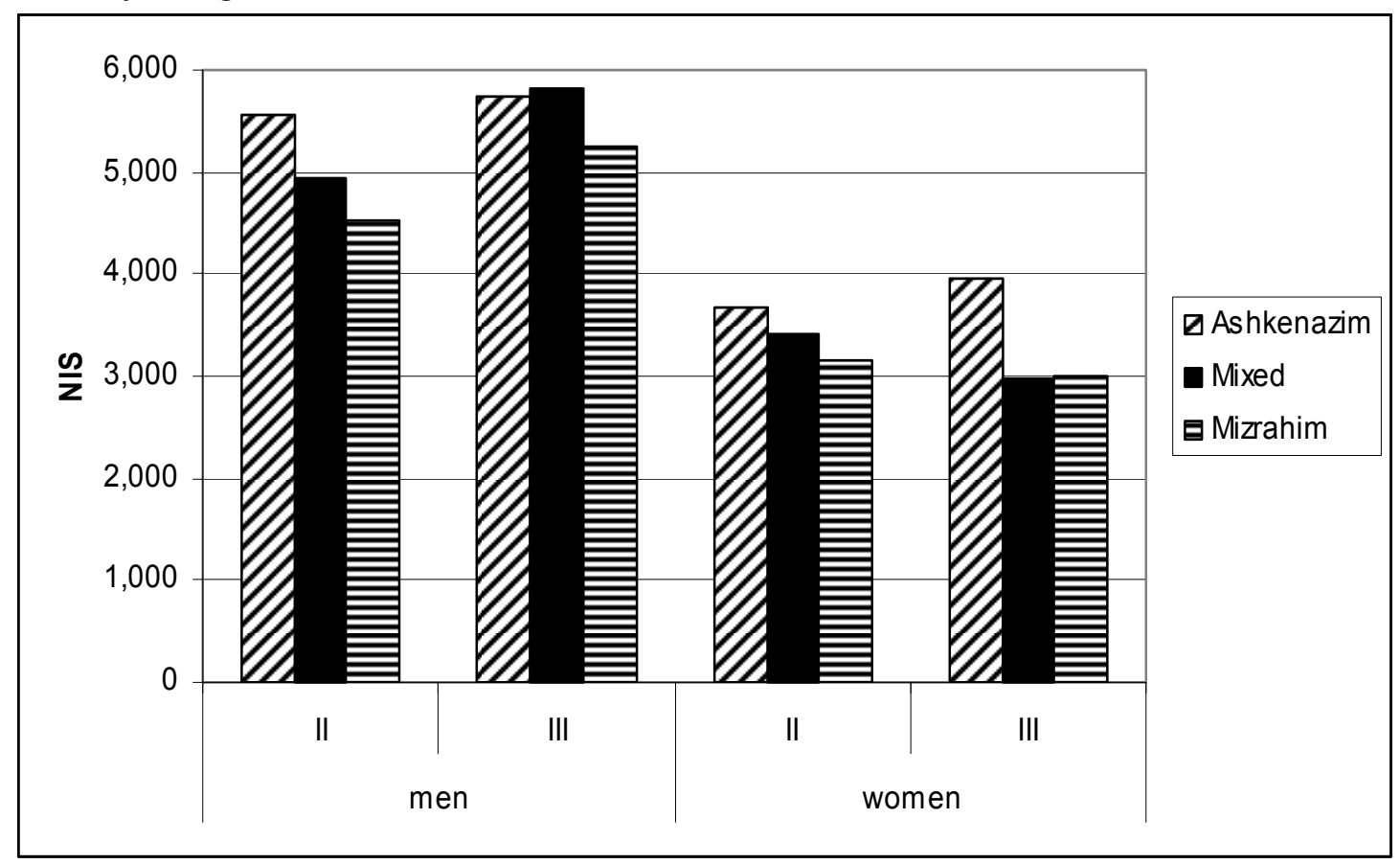

Source: Analysis of the matched 1983-95 Israeli census for salaried workers, 24-35 years old. Persons who worked less than 20 hours or earned less than 1,000 NIS per month were excluded. 